\title{
English Writing Errors Committed by Saudi Students: A Study of Two Female University Groups
}

\author{
Islam Ababneh ${ }^{1}$ \\ ${ }^{1}$ Department of English, University of Hafr Al Batin, Saudi Arabia \\ Correspondence: Islam Ababneh, Department of English, University of Hafr Al Batin, Saudi Arabia. E-mail: \\ islamfe@uhb.edu.sa
}

Received: January 16, 2020 Accepted: February 20, 2020 Online Published: March 17, 2020

doi:10.5539/ijel.v10n3p124 URL: https://doi.org/10.5539/ijel.v10n3p124

\begin{abstract}
The main aim of this study is to highlight the writing errors made by Saudi students majoring in English. The study selected a sample of two groups of female Saudi students residing in two Saudi regions: Tabuk and Hafr Al Batin. The students were requested to write approximately three to four paragraphs about one of three topics related to Saudi Arabia: social media and its effects on Saudi social life, marriage customs in Saudi Arabia, or the economy of Saudi Arabia. In analyzing the collected writing data, the students' writing errors were identified and classified into four categories: grammar type, syntax type, mechanics type, and lexical type errors. Then, the frequency and error percentages of each subcategory were calculated for both groups. The findings show that both groups produced most errors in the subcategory of spelling followed by tenses subcategory even though the students from the University of Hafr Al Batin made overall higher percentages of errors than the errors' percentages made by the students from the University of Tabuk. Further investigation reveals that all students in both regions hardly practice English writing and that Arabic interference contributes to the students' English writing errors. The findings also imply that the curricula specialists at the Saudi ministry of education might consider including more educational material to improve the English writing skills of Saudi university students.
\end{abstract}

Keywords: writing errors, error analysis, Saudi Arabia, Arabs, English writing

\section{Introduction}

Writing skill is considered to be very difficult to be mastered; and it's even more complex when writing in a non-native context. Allen and Corder (1974, p. 177) contend that writing is elaborate, difficult, and is the most complex language ability. Dulay and Burt (1973) explained that errors are the learners' signs of writing development. Taylor (1975) added that errors give important information on how to acquire writing abilities in a language. Al Buainain (2007) elaborated that writing is a dynamic and non-linear process(es). Additionally, Vahdatinejad (2008) explained that there are some analysis techniques that are used to determine what learners need to improve their writing competence. Gass and Selinker (2001) stated that errors act as "red flags" that show some lack of knowledge in a target language.

Jiang Xin and Liu Yanmei studied the errors in Chinese writing in free composition by 32 foreign learners using alphabetic writings. Ancker (2000) explained that there are many reasons for making errors: interference from the native language, complexity of the target language, overgeneralization, and lack of knowledge of some aspects of the target language. Jarvis (2002) explained that discourse factors and linguistic contexts are major causes of systematic errors' occurrences. Many researchers agree that there are two main causes of errors: intralingual (difficulty of the second language) and interlingual (interference from first language). Dulay et al. (1982) explained that intralingual errors are similar to errors made by children learning another target language while Interlingual errors are similar to a semantically equivalent sentence or phrase in the learner's NL. Corder (1967) explained that there are two error types: competence and performance. The competence type of errors is serious because it reflects inadequate learning while the performance errors type is committed by learners when they are hurried or tired. Burt and Kiparsky (1972) distinguished between two errors types: local errors that do not go beyond the sentence level and global errors which obstruct communication and cause discourse confusion. Mungungu (2010) examined English language errors and their frequencies in 360 essays made by 180 Namibian learners of English as a second Language. The results show that the students made errors in articles, tenses, prepositions, and spelling. Darus and Subramaniam (2009) investigated the essay writings errors made by 72 
Malysian students and concluded that most errors are made in terms of: verb tenses, singular/plural nouns, word choice, preposition, word order, and subject-verb agreement. Napitupulu (2017) examined the writing English linguistic errors made by Indonesian students and concluded that native language interference was the cause of committing many errors.

A number of Arab researchers have divulged in the general area of English error analysis and specifically making English writing errors. Al-Khuwaileh and Shoumali (2000) explained that English writing is highly utilized in Arab higher education institutions. Diab (1996) analyzed Arabic interference in the English writings of English foreign language students at the American University in Beirut. Mahmoud (2005) highlighted the "unnatural" use of collocations in English foreign language students' wirings suggesting that most difficulties arise because of interlingual transfer from Arabic. Farooq (1998) studied the Japanese learners' overgeneralization and transfer error patterns of upper-basic written texts, in an English foreign language context. Habash (1982) concluded that Arabic interference is the main cause of common preposition errors in the English writings of UNRWA students. Similarly, Ridha (2012) came to Arabic interference problems in studying the writings of 80 English Foreign language college students. He categorized the errors into four types: word order, lexical-semantic, grammatical, and mechanics. Also, AbiSamra (2003) studied grade 9 school children writings. He categorized their errors into five types: word choice, grammar (articles, prepositions, adjectives, etc.), syntax (sentence structure, word order, coordination, etc.), and mechanics (capitalization, punctuation, and spelling), and discourse type errors. He found that Arabic transfer was the cause of errors to one third of the students. Also, the researcher revealed that there were many errors were in semantics and vocabulary; while the highest number of errors were in syntax, spelling, and grammar. Alkhresheh (2010) studied Jordanian EFL learners syntactic interlingual errors such as word order in a sentence; he concluded that those errors were due to transfer of L1 habit. In a recent study, Hamed (2018) studied the common error types of writing linguistics and their occurrence' frequencies of forty non-English major Libyan students. He found that the causes to be mainly Arabic inference and the incomplete application of rules.

\subsection{Objectives}

Similar to a number of Arab researchers, this study investigates Arab students' English writing errors; but uniquely the study looks into the phenomenon within the context of Saudi students. Specifically, the study has the following objectives:

- It investigates the perception that Saudi university students' writing skills are weak.

- It highlights the specific writing errors committed by two Saudi groups from two public universities.

- It calculates and reveals the writing category of errors with the highest frequency of occurrence.

- It sheds light on some of the causes of poor English writings for Saudi students.

- It makes some recommendations to the Saudi educators to improve the students' English writings.

\section{Method}

\subsection{Research Design}

This study combines both the qualitative and quantitative approaches. Gay, Milla and Airasian (2009) clarified that quantitative research method depends on sampling a large number of participants for valid statistics and interpretation of the collected data; while, the same researchers explained that qualitative research type relies on non-numerical data for analysis and interpretation. Therefore, the qualitative research gives insight into a specific phenomenon by the collection, analysis, and interpretation of comprehensive narrative and visual data.

\subsection{Participants}

A sample of two student groups were selected for conducting a study of English writing errors. Each group consisted of one hundred female Saudi university students in their fourth (level 8) year majoring in English language studies. By distributing a questionnaire to the students, it was found that the students were in the 20-24 years' age category and they had acquired private or public-school schooling before joining a university in the same region where they lived. Also, almost all the students were born and raised within their university region. Additionally, the students had never resided in any other country but only made short family holiday visits to neighboring Arab countries. All the students confirmed that they had never visited any English-speaking country. In brief, the students in both groups came from similar Arabic educational and socioeconomic backgrounds. They spent one required preparatory year at their university to improve their vocabulary, grammar, and English writing. Furthermore, the students had enrolled in some English major courses such as syntax and morphology, semantics, and error analysis as required by their English degree program; error analysis is a linguistic study of 
the errors that learners commit in some target language. Dulay et al. (1982) elaborated that the study of error analysis explains many of the frequent errors committed by learners of a second language including the errors resulting from the first language.

\subsection{Writing Exam}

Three familiar topics related to Saudi Arabia culture were selected for a writing exam. The exam was attempted separately by the two selected group of students. The students at the University of Tabuk attempted the writing exam in the academic year 2016/2017 while the students at the University of Hafr Al Batin wrote the exam in the academic year 2018/2019. The exams were administered by the researcher herself in both cases. The students sat inside a comfortable classroom environment and they were given enough time to organize their thoughts. The students were promoted to use various expressions and phrases in their writings. They were also instructed to pay attention to spelling, grammar, and sentence structures. Then, the students were asked to write between 100 to 150 words about one of the following topics:

- Social media and its effects on Saudi social life

- Marriage customs in Saudi Arabia

- Economy of Saudi Arabia

\subsection{Analysis Procedure}

The papers that the students wrote were collected for further categorizations and analysis. The errors were specified into four categories: grammar, syntax, mechanics, or word choice. Each category was further divided appropriately into few subcategories. The frequency of error occurrences was calculated for each category and for each sub category using Hubbard et al. (1996, pp. 135-141) Taxonomy of common writing errors. Hubbard et al. classified errors into four main categories: grammar, syntax, mechanics, and lexical errors. The grammar errors were then subcategorized into seven subcategories: singular/plural nouns, prepositions, adjectives, tenses, relative clauses, possessive case, and articles. The syntax errors were subcategorized into three subcategories: nouns/pronouns, subject/verb agreement, and word order. The mechanics errors were classified into three sub categories: capitalization, punctuation, and spelling. Finally, the lexical errors were specified into two categories: varied words, and idiom choice or usage.

In conducting the analysis, the errors committed by the students in the two groups were categorized and their frequencies were calculated separately. First, each error was put into the appropriate category/subcategory. Second, the frequency of each error was added up from all students' papers; the frequency is defined as the number of times each error occurs. Third, the percentage of each error occurrence was calculated by dividing the frequency by the number of errors. The same procedure was performed for the papers collected from each group of students.

It must be noted that errors are not the same as mistakes. Ellis (1997) explained that mistakes reflect occasional performance lapses while errors reflect a problem in the learner's knowledge. James (1998) added that a mistake can be self-corrected while errors are likely to occur repeatedly. Errors are not identified by the learner but can be recognized by a teacher. This research assumes that only occurrences of errors exist and the students frequently produce such errors in their writings.

\section{Results and Discussions}

Table 1 shows the categories/subcategories of errors, frequencies of errors, and percentages of errors for each group of students. Overall, the table shows that most errors occurred in the subcategory of spelling (Tabuk: 19.64\%, Hafr: $23.71 \%$ ) followed by tenses (Tabuk: $11.6 \%$, Hafr: $15.81 \%$ ). Surprisingly, the table reveals that the students in both groups made comparable percentage of errors in almost all categories/subcategories. All the students made numerous errors in grammar, syntax, mechanics, and word order categories. The total number of errors made by the Tabuk students was 1344 distributed among four error categories: 570 (42\%) grammar, 171 (13\%) syntax, $513(38 \%)$ mechanics, and $90(7 \%)$ word order while Hafr Al Batin students made 962 total number of errors distributed among the four error categories: 316 (33\%) grammar, 156 (16\%) syntax, 442 (46\%) mechanics, and $48(5 \%)$ word order. The students in Tabuk made more number of errors than Hafr Al Batin students because they wrote more. 
Table 1. Errors' frequencies and their percentages using Hubbard et al. (category/subcategory) taxonomy

\begin{tabular}{llllll}
\hline Category & Subcategories & $\begin{array}{l}\text { Frequency } \\
\text { Tabuk }\end{array}$ & $\begin{array}{l}\text { Percentage (\%) } \\
\text { Tabuk }\end{array}$ & $\begin{array}{l}\text { Frequency } \\
\text { Hafr }\end{array}$ & $\begin{array}{l}\text { Percentage (\%) } \\
\text { Hafr }\end{array}$ \\
\hline Grammar & Tenses & 154 & 11.60 & 152 & 15.81 \\
& Articles & 134 & 9.83 & 38 & 3.96 \\
& Singular/plural & 132 & 9.82 & 20 & 2.08 \\
& Prepositions & 102 & 7.60 & 78 & 8.11 \\
& Adjectives/adverbs & 30 & 2.23 & 14 & 1.46 \\
& Relative clauses & 15 & 1.11 & 6 & 0.63 \\
& possessive case & 3 & 0.22 & 8 & 0.84 \\
Syntax & Subject/verb agreement & 150 & 11.16 & 40 & 4.16 \\
& Nouns or pronouns & 15 & 1.12 & 52 & 5.41 \\
Mechanics & Word order & 6 & 0.45 & 64 & 6.66 \\
& Spelling & 264 & 19.64 & 228 & 23.71 \\
Lexical (word choice) & Punctuation & 129 & 9.60 & 72 & 7.49 \\
Total & Capitalization & 120 & 8.92 & 142 & 14.77 \\
& Varied words & 60 & 4.46 & 42 & 4.37 \\
& Idiom choice or usage & 30 & 2.23 & 6 & 0.63 \\
\hline
\end{tabular}

Figures 1 and 2 show the number of errors in each subcategory made by the University of Tabuk group and by the University of Hafr Al Batin group sorted from maximum to minimum, respectively. It can be observed that both groups committed their most errors in the subcategory of spelling followed by tenses regardless of the number of words they wrote.

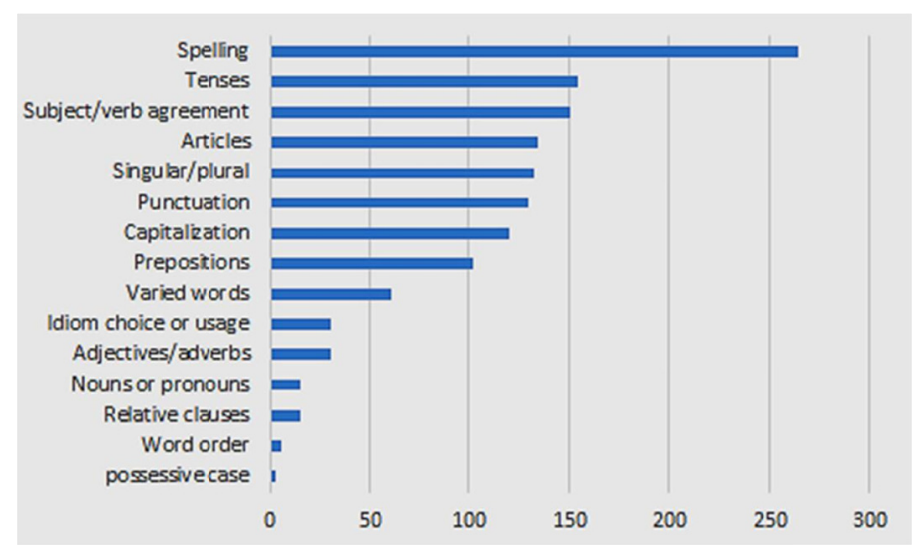

Figure 1. Number of subcategories' errors committed by Tabuk group sorted from maximum to minimum

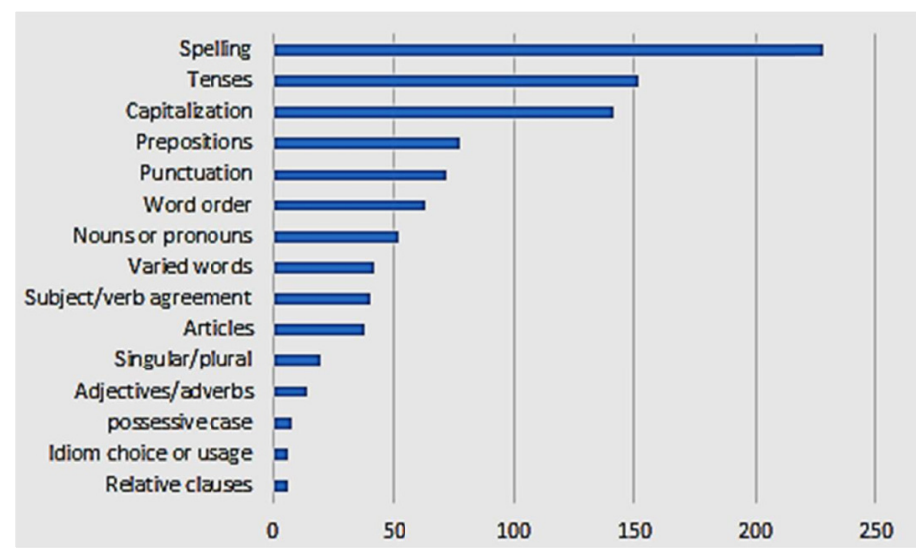

Figure 2. Number of subcategories errors committed by Hafr group sorted from maximum to minimum 


\subsection{Grammar Errors}

The students in both regions made numerous grammatical errors. Mostly, the errors fell in the subcategory of tenses as students could not pick the appropriate tense. Table 2 shows examples of various types of grammatical errors selected from the writings of the students in Tabuk and Hafr Al Batin regions. The table illustrates examples of errors in the seven subcategories of the grammar category. There was $(11.60 \%)$ of errors in tenses by the Tabuk students and (15.81\%) errors in tenses by Hafr Al Batin students. Specifically, the students had problems selecting simple present verbs vs. continuous verbs, simple present/past verbs vs. present/past perfect verbs, deciding if a verb was needed, adding or omitting to be ... etc. The students also had difficulties deciding between singular/plural nouns and using articles. They could not decide whether a noun was countable or not and when to use an article. Also, a decent number of the students could not determine if an article was appropriate and many of them avoided the use of the definite article (the) or the indefinite articles (a, an). For example, many students did not include articles before places, names, or week days. It must be noted that English article usage is completely different from Arabic. There was $(9.82 \%)$ of singular/plural errors and $(9.83 \%)$ of article errors by the Tabuk students; while surprisingly there was $(2.08 \%)$ of singular/plural errors and (3.96\%) of article errors by the students in Hafr Al Batin. Also, the students improperly used prepositions; for example, the students used "in" instead of "on" or used "to" in place of "of" or used "of" instead of "in". The students in Tabuk made (7.60\%) of proposition errors while the students in Hafr Al Batin committed comparable (8.11\%) proposition type of errors. A preposition links a phrase, noun, or a pronoun and other words in a sentence; it represents the spatial, temporal, or logical relationship to the rest of the sentence. Furthermore, the students made less errors in adjectives/adverbs because they tried not to use them in writing their expressions and phrases. There was $(2.23 \%)$ of adjectives/adverbs errors by the Tabuk group while the group in Hafr Al Batin made (1.46\%) of those errors. The students mixed adverbs and adjectives, used nouns instead of adjectives, or misplaced the position of an adjective in a sentence. Finally, there were few possessive case errors and very few relative clauses errors because most of the students avoided using possessions and relative clauses.

Table 2. Examples of grammatical errors from the two regions

\begin{tabular}{|c|c|}
\hline Error type & Examples (errors are between quotations) (... means missing) \\
\hline Prepositions & $\begin{array}{l}\text { Teachers want "of" teach many subjects; Marriage "of" Saudi Arabia; social media have a harm and benefits "of" Saudi } \\
\text { people; It will waste "for" your time; kids do not play "in" their toys; the Comeunecation "in" the paepol; talk with our } \\
\text { frieds and famelis "in" any time; when he live "on" outside country; social is important but we need to control "on" it; } \\
\text { wife should dressing "by" white dress; it is so good "too" the country; we have Too know how “..." use it; it is make use } \\
\text { "To" Talk with our frieds }\end{array}$ \\
\hline $\begin{array}{l}\text { Singular/plural } \\
\text { nouns }\end{array}$ & $\begin{array}{l}\text { There "is" a lot of social media benefits; they were divided into few "part"; there are many "picture"; saudi arabia has } \\
\text { many "company"; It has many positive "influence"; one of the "positive" it has; social media make us open on the } \\
\text { customs of other "country"; you can learn a lot of "thing"; there are a lot of food and "drink" }\end{array}$ \\
\hline $\begin{array}{l}\text { Adjectives/ } \\
\text { Adverbs }\end{array}$ & $\begin{array}{l}\text { Media have "effective positive"; Banks is "danger"; we use it "wrong"; The marriage in saudi arabia very "well" and } \\
\text { different; social media is "benefit" and maybe not "benefit"; this is "unrespected" to their parents }\end{array}$ \\
\hline Tenses & $\begin{array}{l}\text { If we "did" we "will" sit nearer; twitter "taken" time for learning; economy of Saudi is vary "developing"; the wife should } \\
\text { "dressing"; economy "working" very good; social media "have" a harm; social media "is" become; then finally “..." the } \\
\text { wedding; saudi arabia economy “..." the best; how it "is" effects; people became more updates with what “..." happening; } \\
\text { but "..." not good for children; The Saudi Arabia economy “..." very low; saudi arabia "..." many custom very important; } \\
\text { The customs in saudi arabia; maybe its bad or "have" good effect; social media effects of the saudi arabia “..." the Intrnat; } \\
\text { social media "..." the Comeunecation in the paepol }\end{array}$ \\
\hline Possessive case & The "life's" work; with attention and "peoples" comments; the women go to "man" home \\
\hline Relative clauses & $\begin{array}{l}\text { A man "which" get married; hacking people lives "who" relationships; also mention the negitve affect "who" is exposing } \\
\text { the privecy; no one can say "..." the social media is bad or good; they are some bad effects "whose" are standing on their } \\
\text { phone many hours }\end{array}$ \\
\hline Articles & $\begin{array}{l}\text { Social media has "a" advantages; in "the" many countries; social media has "a" side affects; it is for economy of "..." } \\
\text { country; And "the" media can be bad and good; "The" life is very simple; In "the" saudi arabia so much good; “..." effects } \\
\text { of social media have bad thing and good thing; in social life in saudi arabia at "..." same time it has "a" bad effects; "The" } \\
\text { marriage is saudi arabia very well; There are "the" money gaven to woman; when he live on "..." outside country; "the" } \\
\text { social media have effective }\end{array}$ \\
\hline
\end{tabular}

\subsection{Syntax Errors}

The students in both groups generally faced problems in structuring sentences correctly. Syntactically, the students made numerous errors (verb tenses, subject-verb agreement, selecting the right verb form and choosing 
a pronoun for a verb, and wrongly arranging sentences' words). Mostly, the students faced difficulties in writing the right verb for a given subject. There were (11.20\%) subject-verb agreement errors in Tabuk while Hafr Al Batin group made (4.16\%) of these errors. Specifically; a decent number of students in both groups chose the wrong verbs for some subjects, used fragments (part of sentences without verbs or without subject), or committed tenses errors. Examples of the syntax errors include mixing past and present verbs in the same sentence, adding an "s" wrongly to a verb in a sentence, and treating singular phrases such as "social media" as plural ones. Additionally, the students in Tabuk made $(1.12 \%)$ noun/pronoun errors and $(0.45 \%)$ word order errors while the students in Hafr Al Batin made (5.41\%) noun/pronoun errors and (6.66\%) word order errors. Therefore, Hafr Al Batin students made higher percentage of noun/pronoun and word order errors than the students in Tabuk. Examples of noun/pronoun errors include missing a noun/pronoun altogether and misusing the human/nonhuman pronoun. In general, the students' usage of pronouns was not frequent and therefore these types of errors were of low percentage. Table 2 shows examples of the students' errors in the three subcategories of syntax.

Table 3. Syntactic errors examples by the students in the two regions

\begin{tabular}{ll}
\hline Error type & Examples (the errors are between quotations) (.... means missing) \\
\hline Nouns/pronouns & Media "it" has positive effects; saudi arabia "it" is big; the good effect "it's" make us To talk; has "it's" own \\
"castoms; in our country "he the man" want to get marriage; and asked them about "them" daughter; the customs \\
"it" is nice; the "effect" of social media have Tow Things; also "..." has delivered women’s voice to the \\
government; in live the saudi arabia so good and " near for" the city; I feel I am "happiness"; "communicative" \\
between people and "communicative" between cultural; because the "adult they" more dingrous for him; the \\
social media have "effective" in our live \\
Twitter "is" important; social media "have" bad things; people will "have" different customs; social media \\
"have" a harm; there "is" many benefits; saudi arabia "help"; it "help" us; the customs it "is" nice; we "was" very \\
glad; There "are" the money gaven to woman to; There are a lot of food and "drink"; The government "think" in \\
deferent way; the sea "have"; when he "live" on outside country; the social "have" many advantages; the social \\
media "have" effective in our live \\
Negative effect like in SnapChat no private life; he sent always to banks local; life is saudi arabia beautiful; has \\
it’s own "castoms in marriage"; and the different in the world always; there live in the country many of people; it \\
is effect our life in; may some people are funny; became the life easer; in saudi arabia effects social media in life; \\
for marriage women bought the dress white; you can be always with others in communication; The ladies from \\
her relative put the Henna on her hand; changed we ideas and sometime characters; and in the night dance and \\
eat; come them in the home
\end{tabular}

\subsection{Mechanics Errors}

The students had most of their problems in spelling. The students in Tabuk made (19.6\%) spelling errors while the students in Hafr Al Batin made (23.71\%) spelling type errors. It was observed that the students had most spelling problems in the order of two vowels such as " $\mathrm{i}$ " and "e" in a single word, unfamiliar words, mixing some sound words such as "k" and "c" sounds, and in words that have the letter "p" or "b". Unlike the English language, Arabic does not have the "p" letter in its alphabets. Also, Arabic can be described as a phonetic language, which means words are written as they are spelled, which makes spelling in a language such as English with many exceptions more difficult. Thus, the occurrence of a large number of spelling mistakes is most likely due to the students' poor English pronunciation, students' rare daily conversations in English, and students' very rare reading of English material. Verbally, almost all the students professed to do all their readings in Arabic. Furthermore, many students were not familiar with English punctuation rules and mostly avoided using punctuations. Most students used only a period to end sentences or used commas to list things; but did not use any other punctuation symbol. The students in Tabuk made $(9.60 \%)$ punctuation errors while Hafr Al Batin students made (7.49\%) punctuation errors. Additionally, the students had difficulties capitalizing famous words: names of the week and names of cities, words after periods, or pronouns; sometimes the students capitalized words that did not need capitalization. It must be noted that Arabic does not have lower-case or upper-case words. The students in Tabuk made (8.92\%) capitalization errors while the student group in Hafr Al Batin made $(14.77 \%)$ of these errors. Table 4 shows examples of mechanics' errors committed by the students in Tabuk and Hafr Al Batin. The table shows examples of errors within the three subcategories: capitalizations, punctuations, and spelling. 
Table 4. Mechanics errors examples by the students in the two regions

\begin{tabular}{|c|c|}
\hline Error type & Examples (the concerned errors are between quotations) (.... means missing) \\
\hline Capitalization & $\begin{array}{l}\text {... and late. "finally"; positive and "Negative" things; " snapchat and facebook"; "saudi" Arabia; waste the time "." and } \\
\text { harm of the eyes; become "Important" thing; king "salman"; what....”The" customs in saudi arabia; we have "Too" } \\
\text { know how; it is make use "To" Talk with our frieds; "english"; "dammam"; "some Time" } \\
\text { using period instead of comma or vice versa: in real world, In the home; marriage "." and of course not using } \\
\text { appropriately any punctuation: Your family but also others }\end{array}$ \\
\hline Spelling & $\begin{array}{l}\text { Jolessy; vary; speack; weast; wolde; shold; fiends; nais; beatiful; castoms; anytheing; countary; accebt; wight; } \\
\text { dreassing; dudhter; cuntry; vary; bisnesses; ore; oll; intellegent; easer; dpresson; teen agers; espacially; abdated; } \\
\text { baucause; simpal; diffkal; bucous; tow; frieds; famelis; fainly; cheing; comeunection; paepol; goagal; sairsh; } \\
\text { negitve;privecy; beuty;tipical; becous; ageen; femily; peopl; ther; gnral; with out; any one; fowlloing; hapits; deferent; } \\
\text { sourses; every thing; whiat; wnderful; weman; actives; some time; barent; dingrous; thet; opinin; contary; ther; ispecal; } \\
\text { some Time; frest; dowing; thies; tradshenal }\end{array}$ \\
\hline
\end{tabular}

\subsection{Lexical Errors}

Word (lexical) order is defined as the arrangement of words, phrases, and clauses in sentences. In this study, the students mainly wrote simple straightforward sentences and in effect avoided some lexical errors. Both students' groups expressed their ideas using familiar vocabulary with simple verbs and avoided complex structures. The sentences were simple, short, and seldomly with any adjectives or adverbs. The students in Tabuk made a low percentage of about (6\%) lexical errors while the students in Hafr Al Batin had around (5\%) of these errors. Many students improperly arranged verbs and nouns; and that might be due to wrong literal translation from Arabic, which has sentences with reversed verb-noun placement. Some students used the wrong choice of words to express their thoughts; for example, picking the word "wide" when "big" would have been more appropriate. Table 5 illustrates examples of some lexical errors.

Table 5. Lexical errors examples by the students in the two regions

\begin{tabular}{ll}
\hline Error type & Examples (the concerned errors are between quotations) (.... means missing) \\
\hline Using "popular" instead of "famous" & Many "popular" people \\
Using "big" instead of "widely" & Media is very "big" used \\
Using "devil" instead of "bad" & Media is used for good purposes or for "devil" purposes \\
Using "light" instead of "weak" & $\begin{array}{l}\text { Relationship among relatives became "light" } \\
\text { social media has a big "affect" in the "life" of saudi people }\end{array}$ \\
Using "affect" instead of "effect" and using "life" & \\
instead of "lives" & Some of them "get" ther dreams \\
Using "get" instead of "fulfill" & Actually we are following the Islamic "hapits" \\
Using "hapits" instead of "ways" & Mothers usually are the "controlling system" \\
Using a machine type expression for a person & The economy "should be in several sourses" \\
Using "be" instead of "depend" & in social media The food “..." beautiful \\
Using "beautiful" instead of "delicious" & Economy is "high" \\
Improper use of "high" & in saudi arabia very change after "income" social media \\
Using "income" instead of "coming" & from advantages it easy to communication between the "mankind" \\
Using "mankind" instead of "people" &
\end{tabular}

\subsection{Limitations of the Study}

This study has few limitations. First, it does not divulge into the educational background of the students and does not investigate the students' other English language skills. Thus, poor students' English writing skills does not necessarily indicate poor English reading, vocabulary, or grammar. Second, the study does not associate the students' Arabic writing kills with their English writing abilities. Third, the study was only conducted on female students in two regions of Saudi Arabia and might not give a comprehensive understanding of the writing skills of students in other regions inside the country. Fourth, the real reasons of the slight better performance of the Tabuk students might not be known but it was observed by the researcher, who currently resides in Hafr Al Batin and who lived in city of Tabuk for five years, that the city of Tabuk has better educational infrastructure, more professional expatriates, and more emphasis on English literacy. Therefore, a more elaborate study of a larger students' sample in various Saudi areas might give more intelligible understanding of the current English writing abilities for university students inside the kingdom of Saudi Arabia. Briefly, writing is an art that is perfected with many years of hard work and how much of it has been performed prior to conducting this research will never be known; and therefore, all the reasons for Saudi students' poor writing skills will always be vaguely 
understood.

\section{Concluding Remarks}

English writing is perceived by many students and is considered by many educators to be the most challenging and difficult skill to acquire. It requires competence in vocabulary, grammar, and writing techniques. The findings of this study reveal valuable information about the writing kills of Saudi university students. First, the two studied groups made comparative percentage of errors in almost all categories/subcategories and there were insignificant variations among the sampled students. Second, all the students had an inadequate knowledge of English vocabulary and grammar as most of the students' writings contained simple short sentences; even though the students at the University of Tabuk tried to use slightly more complex vocabulary and longer sentences in their writings. About $5 \%$ of the overall students did not write anything or wrote only few words. Nevertheless, it must be noted that the students in Tabuk had relatively less word order errors as well as less structured sentences errors. Third, many of the students in the two regions had their most frequent errors in the subcategory of spelling followed by tenses. Fourth, it was evident that Arabic interference and style of writing played a major factor in the students' English writings. For example, some students used a noun before an adjective similar to their Arabic writing; while some students tried to translate word-for-word Arabic expressions into English. An investigation into the students' literacy habits revealed that other causes of poor writings include lack of English conversations, rare English readings, and very little overall exposure to native speakers of English. In fact, all the students indicated that they communicated in Arabic with their families at home and conversed only in Arabic with their friends at the university. Additionally, the students collectively admitted that they rarely got involved in any English lengthy conversation with anyone at the university campus, home, market, or any other place. Some students professed verbally that they only made short English presentations and answered their professors' questions with few English words during class periods. Therefore, the Ministry of Higher Education should encourage the English teachers in Saudi Arabia to tackle the English writings' shortcomings by developing new writing strategies to be included in the students' curricula, allocating extra practical writing sessions in the syllabus, adding more contextual writings exercises, exposing students to more native English audiovisual materials, and initiating plans to measure students' progress in English writing for the sake of improving students' writing abilities.

\section{References}

AbiSamra, N. (2003). An analysis of errors in Arabic speakers' English writing. In K. Mourtaga (Ed.), Investigating writing problems among Palestinian students studying English as a foreign language. Unpublished doctoral dissertation.

Al-Bauinain, H. (2007). Researching types and causes of errors in Arabic speakers' wrirings. In S. Madraj, A. Jindli \& A. Salami (Eds.), Research in ELT Context (pp. 195-224).

Al-Khuwaileh, A., \& Shoumali, A. A. (2000). Writing Errors: A study of the writing ability of the Arab learners of academic English and Arabic at University. Language, Culture, Curriculum, 13(2), 174-183. https://doi.org/10.1080/07908310008666597

Alkhresheh, M. (2010). Interlingual interference in the English language word order structure of Arab EFL learners. European Journal of Social Sciences, 16(1), 106-113.

Ancker, W. (2000). Forum English Teaching, 38(4), 20-25.

Burt, M., \& Kiparsky, C. (1972). The Gooficon: A repair manual for English. Rowley, Newberry House.

Corder, S. P. (1967). The significance of learners' errors. In J. C. Richards (Ed.), Error analysis: Perspectives on second language acquisition (1984, pp. 19-27). London: Longman.

Corder, S. P. (1974). Error Analysis. In J. P. B. Allen \& S. Pit Corder (Eds.), Techniques in Applied Linguistics (The Edinburgh Course in Applied Linguistics: 3, pp. 122-154), London: Oxford University Press (Language and Language Learning).

Darus, S., \& Subramaniam, K. (2009). Error Analysis of the Written English Essays of Secondary School Students in Malaysia: A Case Study. European Journal of Social Sciences, 8(3), 483-495.

Diab, N. (1996). The transfer of Arabic in the English writings of Lebanese students. Retrieved January 5, 2003, from http://lael.pucsp.br/especialist/181diab.ps.pdf

Dulay, H., \& Burt, M. (1972). You can't learn without goofing: Analysis of children's second language errors. In Richards, J. (1984) (op cit). 
Dulay, H., Burt, M., \& Krashen, S. (1982). Language Two. Oxford University press.

Ellis, R. (1997). Second language acquisition. Oxford: Oxford University Press.

Farooq, M. U. (1998). Contrastive and error analysis-based teaching strategies. Aichi Women's Junior College. Retrieved December 30, 2003 from http://www.cels.bham.ac.uk/resources/essays/farooq2.pdf

Gass, S., \& Selinker, L. (2001). Second language acquisition: an introductory course (chapter 3.2). Mahwah, NJ: LEA.

Gay, L. R., Mills, G. E., \& Airasian, P. W. (2009). Educational research: Competencies for analysis and applications (9th ed.). Upper Saddle River, New Jersey: Prentice Hall.

Habash, Z. (1982). Common Errors in the Use of English Prepositions in the Written Work of UNRWA Students at the End of the Preparatory Cycle in the Jerusalem Area. Retrieved January 2, 2003, from http://www.zeinab-habash.ws/education/books/master.pdf

Hamed, M. (2018). Common Linguistic Errors among Non-English Major Libyan Students Writing. Arab World English Journal, 9, 219-232. https://doi.org/10.24093/awej/vol9no3.15

Hubbard, P., Jones, H., Thornton, B., \& Wheeler, R. (1996). A Training Course for TEFL. Oxford: Oxford University Press.

James, K. (1998). Errors in language learning and use: Exploring errors analysis. London: Longman.

Jarvis, S. (2002). Topic continuity in L2 English article use. Studies in Second Language Acquisition, 24, 387418. https://doi.org/10.1017/S0272263102003029

Mahmoud, A. (August 2005). Collocation errors made by Arab learners of English. Asian EFL Journal, 5.

Mungungu, S. S. (2010). Error analysis: Investigating the writing of ESL Namibian learners. Unpublished Master Thesis, University of South Africa, South Africa.

Napitupulu, S. (2017). Analyzing Linguistic Errors in Writing an English Letter: A Case Study of Indonesian Undergraduate Students. International Journal of Language and Linguistics, 5(3), 71-77. https://doi.org/10.11648/j.ijl1.20170503.12

Ridha, N. (2012). The Effect of EFL Learners' Mother Tongue on their Writings in English: An Error Analysis Study. Journal of the College of Arts (University of Basrah), 60, 22-45.

Taylor, B. P. (1975). The use of overgeneralization and transfer learning strategies by elementary and

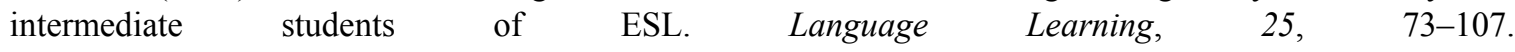
https://doi.org/10.1111/j.1467-1770.1975.tb00110.x

Vahdatinejad, S. (2008). Students' error analysis and attitude towards teacher feedback using a selected software: a case study. Unpublished Master thesis. Universiti Kebangsaan Malaysia, Bangi.

Xiao, X. Q. (2002). An analysis of character errors of foreign learners of Chinese. Chinese Teaching in the World, 2 .

\section{Copyrights}

Copyright for this article is retained by the author, with first publication rights granted to the journal.

This is an open-access article distributed under the terms and conditions of the Creative Commons Attribution license (http://creativecommons.org/licenses/by/4.0/). 